DOI 10.14526/02_2018_308

УДК 796.433.7.

ББК 75.711.73

\title{
АНАЛИЗ СТЕПЕНИ СВЯЗИ МОРФОФУНКЦИОНАЛЬНЫХ ПОКАЗАТЕЛЕЙ В МЕТАНИИ ЛЕГКОАТЛЕТОВ
}

\author{
Кузнецова 3.М. ${ }^{1}$, Кузнецов С.А. ${ }^{2}$, Овчинников Ю.Д. ${ }^{3}$, Головко П.В. ${ }^{3}$ \\ ${ }^{1}$ ФГБОУ ВО «Ульяновский государственньий педагогический университет имени И.Н. \\ Ульянова» \\ Россия, г. Ульяновск, kzm_diss@mail.ru \\ ${ }^{2}$ НЧФ УВО «Университет управления ТИСБИ» \\ Россия, г. Набережные Челны \\ ${ }^{3}$ ФГБОУ ВО «Кубанский государственньй университет физической культуры, спорта и \\ туризма» \\ Россия, г. Краснодар
}

\begin{abstract}
Аннотация. Целенаправленная многолетняя подготовка и воспитание спортсменов высокого класса - сложный процесс, качество которого определяется иелым рядом факторов. Одним из этих факторов является отбор одаренных детей и подростков. Задачи спортивного отбора в метаниях на этапе начального обучения косвенно решались в ряде научных исследований. Обозначенная проблема не потеряла своей научной и практической значимости на современном этапе развития спорта. Эффективность управления спортивной тренировкой во многом зависит от объективности и точности информачии, которой располагает тренер о спортсмене в процессе занятий. Регистрация количественных и качественных показателей физической, технической и других видов подготовки в легкоатлетических метаниях позволит предсказывать спортивные результаты начинающих спортсменов. Материалы. В статье авторы проводят анализ степени связи морфофункииональных показателей со спортивныли достижениями в метании у юношей. Методы исследования: анализ и обобщение научной литературы, анализ морфологических особенностей легкоатлетов, тестирование, методы математической статистики Результаты. Спортсменам, специиализирующимся в метаниях, свойственны определенные морфофункииональные признаки физического развития. На первом этапе подготовки большое значение приобретают продольные размеры тела (верхних и нижних конечностей и их сегментов), особенно для метателей

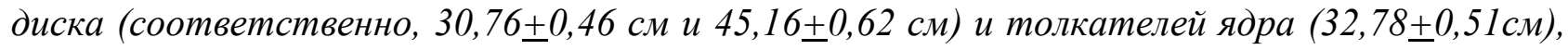
и их соотношение. У метателей диска и толкателей ядра более длинные верхние конечности. Это преимущество наблюдается за счет всех звеньев верхней конечности плеча и предплечья с кистью. Анализ морфологических особенностей легкоатлетов высокого класса выявил высокую связь между показателями строения тела, массы, роста, массоростового индекса, длины конечностей и их сегментов и спортивной специализацией, результативностью спортсменов.
\end{abstract}

Ключевые слова: биомеханика, масса тела, метания, спортивный результат.

Для цитирования: Кузнецова 3.М., Кузнецов С.А., Овчинников Ю.Д., Головко П.В. Анализ степени связи морфофункциональных показателей в метании легкоатлетов. Педагогикопсихологические и медико-биологические проблемы физической культуры и спорта. 2018; 13(2): 54-63. DOI 10.14526/02_2018_308

\section{ANALYSIS OF THE MORPHOLOGICAL-FUNCTIONAL INDICES CONNECTION DEGREE IN THROWING AMONG ATHLETES}




\author{
Kuznetsova Z.M. ${ }^{1}$, Kuznetsov S.A. ${ }^{2}$, Ovchinnikov Yu.D. ${ }^{3}$, Golovko P.V. ${ }^{3}$ \\ ${ }^{1}$ Federal State Budgetary Educational Establishment of Higher Education "Ulyanovsk State \\ Pedagogical University named After I.N. Ulyanov" \\ Russia,Ulyanovsk,kzm_diss@mail.ru \\ ${ }^{2}$ Naberezhnye Chelny Branch of Higher Education Institution " TISBI University of Management» \\ Russia, Naberezhnye Chelny \\ ${ }^{3}$ Federal State Budgetary Educational Establishment of Higher Education "Kuban State University \\ of Physical Culture, Sport and Tourism" \\ Russia, Krasnodar
}

Annotation. A purposeful long-term training and upbringing of high class sportsmen is a difficult process, the quality of which depends on several factors. One of these factors is gifted children and teen-agers selection. The objectives of sports selection in throwing at the stage of initial training were indirectly solved in some scientific research works. This problem is still very urgent and still has its scientific and practical importance at a modern stage of sport development. The effectiveness of managing a sports training mainly depends on objective character and accuracy of information, which a trainer has about a sportsman during the trainings. Quantitative and qualitative indices registration of physical, technical and other kinds of training in athletic throwing will help to predict sports results of sportsmen-beginners. Materials. In the article the authors analyze the degree of morphofunctional indices connection with sports achievements in throwing among young men. Research methods: scientific literature analysis and summarizing, morphological peculiarities of athletes' analysis, testing, methods of mathematical statistics. Results. For sportsmen, who specialize in throwing, it is typical to have morphofunctional features of physical development. At the first stage of training longitudinal body sizes (upper and lower extremities and their segments), become very important especially for discus throwers $(30,76 \pm 0,46$ $\mathrm{cm}$ and $45,16 \pm 0,62 \mathrm{~cm})$ and shot putters $(32,78 \pm 0,51 \mathrm{~cm})$, and their ratio. Discus throwers and shot putters have longer upper extremities. This advantage is observed owing to all parts of the upper extremity - a shoulder and forearm with a hand. High class athletes' morphological peculiarities analysis revealed a high connection between the indices of body constitution, weight, height, weight-height index, extremities length and their segments and sports specialization and sportsmen's effectiveness. Conclusion. For athletes who specialize in throwing, it is typical to have morphofunctional features of physical development. At the first stage of training longitudinal body sizes (upper and lower extremities and their segments), become very important especially for discus throwers $(30,76+0,46 \mathrm{~cm}$ and 45,16+0,62 cm) and shot putters $(32,78+0,51 \mathrm{~cm})$, and their ratio. Discus throwers and shot putters have longer upper extremities. This advantage is observed owing to all parts of the upper extremity - a shoulder and forearm with a hand.

Keywords: biomechanics, body weight, throwing, sports result.

For citations: Kuznetsova Z.M., Kuznetsov S.A., Ovchinnikov Yu.D., Golovko P.V. Analysis of the morphological-functional indices connection degree in throwing among athletes. The Russian Journal of Physical Education and Sport (Pedagogico-Phycological and Medico-Biological Problems of Physical Culture and Sports). 2018; 13(2): 53-62. DOI 10.14526/02_2018_308

Целенаправленная многолетняя подготовка и воспитание спортсменов высокого класса - сложный процесс, качество которого определяется целым рядом факторов. Одним из этих факторов является отбор одаренных детей и подростков.
Задачи спортивного отбора в метаниях на этапе начального обучения косвенно решались в ряде научных исследований, проводимых такими учеными, как Пресс Т.Н., Комарова А.Д., Возняк В.С., Тутевич В. Н., Туманян Г.С. и другими $[3,6,8]$. Обозначенная проблема не потеряла своей 
научной и практической значимости на современном этапе развития спорта высших достижений и совершенствования педагогического мастерства, однако уже длительное время не освещалась в научных публикациях. Получили развитие научные исследования, направленные на психологическую помощь и оценку информативности показателей физической работоспособности и двигательной подготовленности детей $[4,5,6,11]$. Это указывает на узкопрофильность и специфику развития данного вида спорта, его некультивируемость в стране, недостаточную пропаганду среди молодежи и, как следствие, на отсутствие развернутых научных исследований с применением многофакторного анализа. Данный вид спорта требует возрождения былых спортивных позиций, и начинать работу необходимо с анализа спортивного отбора.

Эффективность

управления спортивной тренировкой во многом зависит от объективности и точности информации, которой располагает тренер о спортсмене в процессе занятий (Грощенков С.С.; Хань Чао, Хао Цзюнь) $[2,5,6,11]$. Регистрация количественных и качественных показателей физической, технической и других видов подготовки в легкоатлетических метаниях позволит предсказывать спортивные результаты начинающих спортсменов.

Выводы ряда экспериментальных работ, посвященных изучению влияния морфологических особенностей метателей на результаты двигательных заданий, разнятся. Так, в метании тяжелых снарядов (ядро, молот) между массой тела и спортивным результатом найдена положительная связь [2], а между массой тела и прыгучестью зависимости не обнаружено [1]. Биомеханическое качество «быстрота» выполняемых движений находится в обратной зависимости от массы тела. С увеличением массы тела снижаются результаты в силовых и скоростно-силовых упражнениях, связанных с перемещением собственного тела в пространстве (Костюченко В.Ф., Врублевский Е.П., Боровая В.А) [4].

О влиянии длины и массы тела метателя на угол вылета, начальную скорость и дальность полета снаряда идет речь в научной работе В.Н. Тутевича [10]. Дальность полета снаряда в метаниях зависит от скорости его вылета. Из второго закона Ньютона вытекает, что скорость вылета снаряда пропорциональна силе и времени ее приложения (масса снаряда постоянна). Следовательно, метатели должны обладать высокими показателями мышечной силы и иметь длинные рычаги, увеличивающие время приложения силы к снаряду. Тем не менее некоторые тренеры считают, что для метателей диска эти факторы не являются определяющими, так как из-за легкости снаряда результаты зависят в основном от уровня скоростных качеств метателей [4].

По данным Комаровой А.Д., при отборе спортсменов в группу метателей необходимо обращать внимание на детей среднего и выше среднего роста (для своей возрастной группы) с достаточно развитой мускулатурой и пропорциональным соотношением отдельных частей тела $[3,7,8]$. Рост девочек в 12-13 лет должен быть не меньше 168-170 см, а мальчиков 170-175 см, вес тела - небольшой, так как дети с большой мышечной массой не обладают достаточной силой и подвижностью нервных процессов. Для дискоболов важно учитывать ширину плеч, для метателей молота большое значение имеет длина рук, а ширина плеч практически преимуществ не дает. Обращая внимание на рост будущих метателей, следует учитывать не только имеющиеся данные, но и потенциальные возможности изменения этого важнейшего показателя.

Потенциальные возможности роста тела в длину можно определить по длине кисти и стоп (Криволапчук И.А., Чернова М.Б., Герасимова А.А., Баранцев С.А., Мышъяков В.В., Просянкин В.В.) [5]. Если у новичка даже невысокого роста большие кисти рук и ступни ног, то можно 
рассчитывать на значительное увеличение роста спортсмена в будущем.

Аулик И.В. утверждает, что отбор, основанный только на оценке уровня развития физических качеств, малоэффективен [1]. Научные исследования показывают, и практический опыт подтверждает научные прогнозы, что в детстве, в подростковом и даже юношеском возрасте лучшие результаты просматриваются не у наиболее способных и перспективных, а у тех, кто значительно опередил своих сверстников по биологическому возрасту, причем темпы развития носят строго индивидуальный характер (Ловягина А.Е.) [6].

По данным известных ученых Комаровой А.Д., Пресс Т.Н., Туманян Г.С.,

Мартиросова Э.Г., для достижения выдающихся результатов в метаниях имеют существенное значение антропометрические показатели: рост, масса тела, размах рук $[3,8,9$, с.55].

При определении морфофункциональных признаков, определяющих способность к занятиям легкоатлетическими метаниям, нами использовались научные методы, доказывающие объективность проведенных исследований.

При

антропометрических исследовались 3 группы взаимосвязанных показателей, позволяющих объективно увидеть результаты научных исследований (антропометрический метод).

Таблица 1 - Группы антропометрических характеристик

\begin{tabular}{|c|c|c|c|}
\hline №п/п & Продольные размеры тела: & Тотальные размеры тела & $\begin{array}{c}\text { Поперечные размеры } \\
\text { тела }\end{array}$ \\
\hline 1. & длина тела (рост стоя), & вес тела, & $\begin{array}{c}\text { Акромиальный диаметр } \\
\text { (ширина плеч) }-\end{array}$ \\
\hline 2. & $\begin{array}{c}\text { длина верхней части тела } \\
\text { (рост сидя) }\end{array}$ & $\begin{array}{c}\text { Тазогребневый диаметр } \\
\text { (ширина таза) }\end{array}$ \\
\hline 3. & длина туловища & обхват груди & \\
\hline 4. & длина руки & & \\
\hline 5. & длина плеча & & \\
\hline 6. & длина предплечья & & \\
\hline 7. & длина кисти & & \\
\hline 8. & длина ноги & & \\
\hline 9. & длина бедра & & \\
\hline 10. & длина голени & & \\
\hline 11. & длина стопы & & \\
\hline
\end{tabular}

Значение указанной в таблице терминологии:

Акромиальный диаметр (ширина плеч) расстояние между правой и левой акромиальными точками (при измерении плечи не должны быть сильно приподняты или опущены).

Тазогребневый диаметр (ширина таза) расстояние между правой и левой подвздошно-гребневыми точками.
Поперечный диаметр груди - расстояние между наиболее выступающими боковыми частями ребер.

Переднезадний диаметр груди расстояние между нижнегрудинной точкой и остистым отростком позвонка, лежащего в этой же горизонтальной плоскости.

Поперечный диаметр нижней части плеча - наибольшее расстояние между наружным и внутренним надмыщелками плечевой кости. 
Поперечный диаметр нижней части предплечья - наибольшее расстояние между шиловидными отростками лучевой и локтевой костей.

Поперечный диаметр нижней части бедра - наибольшее расстояние между внутренним и наружным надмыщелками бедренной кости.

Методы математической статистики применялись с целью объективного обоснования надежности и достоверности количественных характеристик исследуемых величин. Статистическая обработка экспериментального материала включала вычисление следующих величин:

$\checkmark$ средняя

арифметическая

величина;

$\checkmark$ ошибка средней арифметической величины;

$\checkmark$ среднеквадратическое

отклонение;

$\checkmark$ ошибка

среднего

квадратического отклонения;

$\checkmark$ коэффициент вариации;

$\checkmark$ критерий Стьюдента для

выявления достоверности различий сравниваемых результатов.

В исследовании приняли участие 54 юных спортсмена в возрасте от 13 до 16 лет. Из них 27 новичков, 10 имеют 2-й юношеский разряд, 14 человек - 1-й юношеский разряд и 6 человек - 3-й взрослый разряд.

Большое значение в процессе отбора легкоатлетов специалисты придают морфологическим особенностям. Анализ морфологических особенностей легкоатлетов высокого класса выявил высокую связь между показателями строения тела, массы, роста, массоростового индекса, длины конечностей и их сегментов и спортивной специализацией, результативностью спортсменов.

Длина тела как интегральный показатель становления организма в ряде видов спорта играет существенную роль (Тотальные размеры тела.). Полученная взаимосвязь между длиной тела и спортивным результатом у юношей свидетельствует о значительном влиянии этого показателя на спортивный результат в метании диска и в толкании ядра (ч = $0,724-0,726)$.

Связь показателей парной корреляции длины тела и спортивного результата юных легкоатлетов с возрастом, a, следовательно, с повышением спортивной квалификации увеличивается, достигая максимума в 15-летнем возрасте.

В исследованных видах юношеских метаний отмечена достоверная связь массы тела со спортивным результатом (ч $=0,563-0,580)$. В связи со сложностью компонентов состава массы тела корреляция средней величины, с общей закономерностью к увеличению связи с возрастом и спортивной тренировкой.

Продольные размеры тела, особенно конечностей и их звеньев, являясь костными рычагами, могут оказывать существенное влияние на спортивное мастерство юных метателей. Значительная степень обусловленности этих показателей наследственностью дает надежную информацию для использования их в тренерской практике в качестве тестов для отбора.

Характеризуя взаимосвязь продольных размеров верхней конечности и ее звеньев, можно отметить, что взаимосвязь этих показателей со спортивным результатом в метании неодинакова.

Наибольшая связь, увеличивающаяся с возрастом, между показателем длины руки и результатом в метании отмечена в толкании ядра и метании диска (ч $=0,459-0,507)$.

Значительная степень связи длины плеча со спортивными результатами имеет место в метании диска и толкании ядра (ч $=0,636-0,746)$, в метании копья этот показатель существенного значения для достижения результатов не имеет (ч $=$ $0,329)$.

Следует заметить, что длина плеча по сравнению с длиной руки имеет большее значение в метании диска и толкании ядра. 
Что касается длины предплечья, то его значение для достижения мастерства в метании невелико, теснота связи колеблется в пределах средних величин (ч $=0,302-0,402)$.

Корреляционная связь между длиной кисти и спортивным результатом достоверна в толкании ядра и метании диска (ч $=0,422-0,452)$, в метании копья она ниже границ достоверности (ч = 0,403).

Характеризуя взаимосвязь верхней конечности и ее звеньев со спортивным результатом, можно отметить, что значение этого показателя для достижения результатов в метании неодинаково.

Наибольшая связь, увеличивающаяся с возрастом, между показателем длины рук и результатом в метании отмечена в толкании ядра и метании диска (ч=0,459-0,507).

Значительная степень связи длины плеча со спортивными результатами имеет место в метании диска и толкании ядра (ч $=0,636-0,746)$, в метании копья этот показатель существенного значения для достижения результатов не имеет (ч $=$ 0,329).

Следует заметить, что длина плеча по сравнению с длиной руки имеет большее значение в метании диска и толкании ядра.

Что касается длины предплечья, то его значение для достижения мастерства в метании невелико, теснота связи колеблется в пределах средних величин (ч $=0,302-0,402)$.

Корреляционная связь между длиной кисти и спортивным результатом достоверна в толкании ядра и метании диска (ч $=0,422-0,452)$, в метании копья она ниже границ достоверности (ч = 0,403).

Характеризуя взаимосвязь верхней конечности и ее звеньев со спортивным результатом, можно отметить, что это значение для достижения результатов в метании неодинаково. Достоверная связь между длиной верхней конечности и ее сегментов, преимущественно длины плеча, со спортивным результатом отмечается в метании диска и толкании ядра, в метании копья эта связь незначительна, что, на наш взгляд, может быть следствием недостаточного владения техническим мастерством юными метателями копья.

Между длиной ноги и спортивным результатом связь достоверна в толкании ядра и метании диска (ч $=0,465-0,515)$, в метании копья она выражена слабо (ч = 0,217).

Связь между длиной бедра и спортивным результатом значительна в толкании ядра и метании диска (ч $=0,478-$ $0,481)$. Аналогична связь результата с длиной стопы, хотя значение коэффициента корреляции (ч $=0,482-$ $0,585)$ выше, чем с длиной голени, а это важно для обеспечения необходимой площади опоры.

Характеризуя взаимосвязь нижней конечности и ее звеньев со спортивным результатом, можно отметить, что наиболее существенное значение из сегментов нижней конечности имеет длина бедра, т.е. как и на верхней конечности, проксимальное звено, особенно для метателей диска и толкателей ядра.

Поперечные размеры тела. Из поперечных размеров тела анализу подвергалась ширина плеч и таза, из которых первый параметр характеризует развитие мускулатуры и тип сложения, а второй - устойчивость тела спортсмена при выполнении метания.

Корреляция между исследуемым показателем ширины плеч и спортивным результатом наиболее существенна в толкании ядра и метании диска (ч $=0,542-$ $0,685)$. В метании копья она достоверна лишь в 16-летнем возрасте (ч=0,412).

Корреляционная связь между показателем ширины таза и спортивным результатом существенна во всех видах метания (ч $=0,425-0,541)$.

Анализируя взаимосвязь ширины плеч и таза со спортивным результатом, можно отметить, что если ширина плеч имеет наибольшее значение и в метании диска и толкании ядра, то ширина таза 
имеет значение во всех исследуемым метаниях.

Сопоставление

морфофункциональных признаков физического развития юных метателей позволило установить ряд существенных закономерностей.

По длине тела метатели диска и толкатели ядра превосходят толкателей копья. Аналогичная связь отмечается и при оценке окружности груди.

Наибольшую массу тела имеют толкатели ядра и метатели диска. У всех групп юных метателей вес тела увеличивается неравномерно и неоднозначно.

У юных метателей диска более длинные верхние конечности (это наблюдается по сравнению с толкателями ядра во всех звеньях верхних конечностей - плече и предплечье, кисти), которые образуют биомеханический рычаг, благоприятствующий метанию. Эта представителей других видов метаний, хотя различия между показателями дискоболов и толкателей ядра невелика. Отсюда можно предположить, что для последних двух групп этот показатель имеет наиболее существенное значение, что подтверждает и коэффициент вариативности этого параметра, который значительно меньше, чем у метателей копья. Что касается ширины таза, то существенных различий в этом показателе у метателей нет. Результаты средней величины, стандартного отклонения и прироста размаха рук у юных метателей представлены в таблице 2 .

По охватным размерам сегментов конечностей плеча, предплечья, бедра и голени метатели копья и толкатели ядра имеют более высокие показатели, чем дискоболы. закономерность сохраняется во всех возрастных группах.

В длине нижних конечностей аналогичные различия обнаруживаются между метателями копья, дискоболами, с одной стороны, и толкателями ядра, с другой. Различия имеют место в длине бедра. Такое соотношение звеньев нижних конечностей необходимо для обеспечения устойчивости метателей. Средняя величина голени способствует более низкому, при значительной величине длины тела у толкателей ядра и дискоболов, опусканию ОЦТТ, что приводит к большой устойчивости позы метателей, a более длинное бедро увеличивает площадь опоры, создавая возможность перемещения тела во время движения по кругу со снарядом без потери равновесия.

Во всем исследованном возрастном диапазоне ширина плеч у метателей диска превалирует над шириной плеч

Различие в развитии мускулатуры бедра обусловлено специфической работой его мышц. У метателей тяжелых снарядов (копье, толкание ядра) обхват бедра больше, чем у метателей диска. В периметрах голени существенных различий между метателями не обнаружено.

Наибольшую связь из антропометрических показателей со спортивным результатом в метании имеет размах рук юных спортсменов в метании диска $(0,204,0,551$, $0,746,0,827)$ и толкании ядра $(0,161,0,545$, $0,633,0,798)$. В метании копья $(0,173$, 0,588, 0,662, 0,823) количественное выражение этой связи увеличивается до 16-летнего возраста. Корреляционная зависимость между размахом рук и спортивным результатом юных метателей представлена в таблице 3 .

Таблица 2 - Средняя величина (M), стандартное отклонение (Q) и прирост размаха рук у юных метателей

\begin{tabular}{|c|c|c|c|c|c|c|c|c|c|}
\hline \multirow{3}{*}{ Возраст } & \multicolumn{9}{|c|}{ Виды метаний } \\
\hline & \multicolumn{3}{|c|}{ копье } & \multicolumn{3}{|c|}{ диск } & \multicolumn{3}{|c|}{ ядро } \\
\hline & $\mathrm{M}$ & $\mathrm{Q}$ & прирост & $\mathrm{M}$ & $Q$ & прирост & $\mathrm{M}$ & $Q$ & прирост \\
\hline
\end{tabular}




\begin{tabular}{|c|c|c|c|c|c|c|c|c|c|}
\hline 13 & 179,69 & 14,93 & - & 194,94 & 13,54 & - & 182,89 & 14,50 & \\
\hline 14 & 186,57 & 16,62 & 6,88 & 193,34 & 15,79 & 9,40 & 190,73 & 16,24 & 7,84 \\
\hline 15 & 197,33 & 13,15 & 10,76 & 206,5 & 12,37 & 12,19 & 202,69 & 12,75 & 11,95 \\
\hline 16 & 207,82 & 14,36 & 10,48 & 218,51 & 13,09 & 11,98 & 204,06 & 14,03 & 11,38 \\
\hline
\end{tabular}

Таблица 3 - Корреляционная зависимость между размахом рук и спортивным результатом юных метателей

\begin{tabular}{|c|c|c|c|}
\hline \multirow{2}{*}{$\begin{array}{c}\text { Возраст } \\
\text { спортсмена }\end{array}$} & \multicolumn{3}{|c|}{ Виды метаний } \\
\hline 13 & копье & диск & ядро \\
\hline 14 & 0,173 & 0,204 & 0,161 \\
\hline 15 & 0,588 & 0,581 & 0,545 \\
\hline 16 & 0,662 & 0,746 & 0,683 \\
\hline
\end{tabular}

\section{Спортсменам,} специализирующимся свойственны морфофункциональные

в метаниях, определенные признаки физического развития. На первом этапе подготовки большое значение приобретают продольные размеры тела (верхних и нижних конечностей и их сегментов), особенно для метателей диска (соответственно, 30,76 $\pm 0,46$ см и $45,16 \pm 0,62$ см) и толкателей ядра $(32,78 \pm 0,51 \mathrm{~cm})$ и их соотношение. У метателей диска и толкателей ядра более длинные верхние конечности. Это преимущество наблюдается за счет всех звеньев верхней конечности - плеча и предплечья с кистью.

\section{Список литературы}

1. Аулик И.В. Определение физической работоспособности в клинике и спорте. М.: Медицина. 1979: 192.

2. Грощенков С.С. О возможности дальнего прогноза спортивной пригодности. Теория и практика физической культуры. 2002; 6: 44-46.

3. Комарова А.Д. Отбор метательниц. Легкая атлетика. 1992; 2: 14-16.

4. Костюченко В.Ф., Врублевский Е.П., Боровая В.А. Классификация специальных упражнений, применяемых в тренировке метателей (на примере метания копья). Ученые записки университета им. П. Ф. Лесгафта. 2014; 5 (111): 70-77.

5. Криволапчук И.А., Чернова М.Б., Герасимова А.А., Баранцев С.А., Мышъяков В.В., Просянкин В.В. Оценка информативности показателей физической работоспособности и двигательной подготовленности детей 11-12 лет на основе факторного анализа. Новые исследования. 2015; 1 (42): 55-61.
6. Ловягина А.Е. Проблемы психологической помощи в спортивном отборе. Вестник Санкт-Петербургского университета. Серия 12. Психология. Социология. Педагогика. 2013; 1: 35-39.

7. Мирошникова Ю.В., Самойлов А.С., Ключников С.О., Выходец И.Т., Бехтина В. Медико-биологическое обеспечение в детскоюношеском спорте в Российской Федерации (концепция). Педиатрия. Журнал им. Г. Н. Сперанского. 2013; 92: 1: 143-148.

8. Пресс Т.Н., Комарова А.Д. Взаимосвязь спортивного результата и уровня развития физических качеств у юных спортсменовметательниц. Теория и практика физической культуры. 1974; 8: 36-38.

9. Туманян Г.С., Мартиросов Э.Г. Телосложение и спорт : научно-популярная литература. М.: Физкультура и спорт. 1976: 239.

10. Тутевич В.Н. Основы теории спортивных метаний : Автореф. дис. ... д-ра педагогических наук. / В. Н. Тутевич. М. 1969: 55.

11. Хань Чао, Цзюнь Хао. Формирование готовности к соревнованию метателей копья. Ученые записки университета им. П. Ф. Лесгафта. 2010; 12 (70): 112-115.

12. Кузнецова 3.М., Овичнников Ю.Д., Хорькова Л.В. Исследование периода усталости в тренировочном процессе у женщин-боксеров. Педагогико-психологические и медикобиологические проблемы физической культуры и cnopma. 2017; 12(1): 14-21. URL: http://www.journalscience.org/ru/article/720.html.

DOI 10.14526/01_2017_177.

13. Гранкин Н.А. Кузнецова 3.M. Показатели функционального состояния и резервных возможностей организма курсантов. Педагогико-психологические и медикобиологические проблемы физической культуры $u$ cnopma. 2017; 12(3): 37-46. URL: http://www.journalscience.org/ru/article/835.html.

DOI 10.14526/03_2017_232. 
14. Kuznetsova Z., Kuznetsov A., Mutaeva I., Khalikov G., Zakharova A., 2015. Athletes training based on a complex assessment of functional state. In Proceedings of the $3^{\text {rd }}$ International Congress on Sport Sciences Research and Technology support. SCITEPRESS. P. 156-160 (Scopus).

15. Kuznetsov A., Mutaeva I., Kuznetsova Z., 2017. Diagnostics of Functional State and Reserve Capacity of young Athletes' Organism. In Proceedings of the $5^{\text {th }}$ International Congress on Sport Sciences Research and Technology support. SCITEPRESS. P. 111-115 (Scopus).

\section{References}

1. Aulik I.V. Opredelenie fizicheskoj rabotosposobnosti v klinike I sporte [Physical working capacity determination in a clinic and sport]. Moscow: Medicine. 1979: 192.

2. Groshchenkov S.S. About the opportunity of further sports fitness prediction / S. S. Groshchenkov. Teoriya I praktika fizicheskoj kul'tury $=$ Theory and practice of physical culture. 2002; 6: 4446 [In Russ., In Engl.].

3. Komarova A.D. Female throwers selection. Legkaya atletika. 1992; 2: 14-16 [In Russ.].

4. Kostyuchenko V.F., Vrublevskij E.P., Borovaya V.A. Special exercises classification, which are used in training of throwers (by the example of javelin throwing). Uchenye zapiski Universiteta imeni P.F. Lesgafta. 2014; 5(111): 70-77 [In Russ.].

5. Krivolapchuk I.A., Chernova M.B., Gerasimova A.A., Barantsev S.A., Mysh'yakov V.V., Prosyankin V.V. Informativity estimation of physical working capacity and motional readiness indices among 11-12-year-old children on the basis of factorial analysis. Novye issledovaniya. 2015; 1(42): 55-61 [In Russ.].

6. Lovyagina A.E. The problems of psychological help in sports selection / A. E. Lovyagina. Vestnik Sankt-Peteburgskogo Universiteta. Seriya 12. Psihologiya. Sociologiya. Pedagogika. 2013; 1: 35-39 [In Russ.].

7. Miroshnikova Y.V., Samoylov A.S., Klyuchnikov S.O., Vykhodets I.T., Bekhtina V. Medical-biological support in sport for children and teen-agers in the Russian Federation (conception). Zhurnal "Pediatriya" imeni G.N. Speranskij = Journal "Pediatrics" named after G. N. Speranskiy. 2013; 92: 1: 143-148 [In Russ., In Engl.].
8. Press T.N., Komarova A.D. Sports result interconnection with the level of physical qualities development among young female sportsmen-throwers. Teoriya I praktika fizicheskoj kul'tury = Theory and practice of physical culture. 1974; 8: 36-38 [In Russ., In Engl.].

9. Tumanyan G.S., Martirosov E.G. Teloslozhenie I sport: nauchno-populyarnaya literatura [Constitution and sport: popular scientific literature]. Moscow: Physical culture and sport. 1976: 239.

10. Tutevich V.N. The basis of sports throwing theory. Doctor's thesis. Moscow. 1969: 55.

11. Han Chao, Jun Hao. Readiness for competition formation among javelin throwers. Uchenye zapiski Universiteta imeni P.F. Lesgafta. 2010; 12(70): 112-115 [In Russ.].

12. Kuznetsova Z.M., Ovchinnikov Yu.D., Khorkova L.V. Fatigue period study in training process among female boxers. Pedagogiko-psihologicheskie I mediko-biologicheskie problem fizicheskoj kul'tury I sporta = Pedagogico-psychological and medicobiological problems of physical culture and sports. 2017; 12(1): 14-21. URL: http://www.journalscience.org/ru/article/720.html.

DOI 10.14526/01_2017_177 [In Russ., In Engl.].

13. Grankin N.A., Kuznetsova Z.M. Functional state and reserve capacities indices of cadets' organism. Pedagogiko-psihologicheskie I mediko-biologicheskie problem fizicheskoj kul'tury I sporta = Pedagogico-psychological and medicobiological problems of physical culture and sports 2017; 12(3): 37-46. URL: http://www.journalscience.org/ru/article/835.html.

DOI 10.14526/03_2017_232 [In Russ., In Engl.].

14. Kuznetsova Z.M., Kuznetsov A., Mutaeva I., Khalikov G., Zakharova A., 2015. Athletes training based on a complex assessment of functional state. In Proceedings of the $3^{\text {rd }}$ International Congress on Sport Sciences Research and Technology support. SCITEPRESS. P. 156-160 (Scopus).

15. Kuznetsov A., Mutaeva I., Kuznetsova Z., 2017. Diagnostics of Functional State and Reserve Capacity of young Athletes' Organism. In Proceedings of the $5^{\text {th }}$ International Congress on Sport Sciences Research and Technology support. SCITEPRESS. P. 111-115 (Scopus).

Подано: 06.02.2018

Кузнецова Зинаида Михайловна - доктор педагогических наук, профессор, Федеральное государственное бюджетное образовательное учреждение высшего образования «Ульяновский государственный педагогический университет имени И.Н. Ульянова», 432700, 2. Ульяновск, Россия, площуадь 100-летия со дня рождения В.И. Ленина, дом 4, е-таil: kzm_diss@mail.ru

Кузнецов Станислав Александрович - кандидат педагогических наук, старший преподаватель, Набережночелнинский филиал учреждения высшего образования 
«Университет управления ТИСБИ», 423800, Россия, г. Набережные Челны, ул. Татарстан, дом 10

Овчинников Юрий Дмитриевич - кандидат технических наук, доцент, Федеральное государственное бюджетное образовательное учреждение высшего образования «Кубанский государственный университет физической культуры, спорта и туризма», г. Краснодар, Россия, 350015, ул. Буденного, дом 161

Головко Петр Вячеславович - студент, Федеральное государственное бюджетное образовательное учреждение высшего образования «Кубанский государственныи университет физической культуры, спорта и туризма», г. Краснодар, Россия, 350015, ул. Буденного, дом 161

DOI 10.14526/02_2018_309

УДК 796.83

ББК 75.1

\title{
РАЗВИТИЕ КООРДИНАЦИОННЫХ СПОСОБНОСТЕЙ В ПРОЦЕССЕ СПОРТИВНОЙ ТРЕНИРОВКИ ЗАНИМАЮЩИХСЯ СПОРТИВНЫМИ ВИДАМИ ЕДИНОБОРСТВ С ПРИМЕНЕНИЕМ СПЕЦИФИЧЕСКИХ ДВИГАТЕЛЬНЫХ ТРЕНИРОВОЧНЫХ ЗАДАНИЙ
}

\author{
Миниханов В. . $^{1}$ \\ ${ }^{1}$ Федеральное государственное бюджетное образовательное учреждение выстего \\ образования «Российский университет транспорта (МИИТ)» \\ Россия, Москва,vlminih@mail.ru
}

\begin{abstract}
Аннотация. Высокий уровень развития координационных способностей необходим для спортсменов практически во всех видах прикладных единоборств, поскольку высокие возможности управления своими координационными способностями позволяют рационально проводить технические действия и определяют спортивный результат. От развития координачии в решающей степени зависит успешность обучения новым двигательным действиям и совершенствования их усвоенных форм, проявляюшихся во всех сферах двигательной деятельности. Материалы. Разработка и экспериментальное обоснование методики развития координационных способностей в прочессе спортивной тренировки занимающихся спортивными видами единоборств с применением специфических двигательных тренировочных заданий. Методологической основой проведения работьл явилось построение движений в соответствии с концепцией многоуровневой системь управления произвольными движениями Н.А. Бернштейна. Методы исследования: анализ и обобщение научной литературы, теоретический анализ и обобщение многолетнего опыта спортивной тренировки и работы со студентами сборных команд в качестве стариего тренера Российского университета транспорта по видам спортивных единоборств. Результаты. $B$ результате теоретического и экспериментального исследования разработана методика развития координационных способностей в процессе спортивной тренировки занимающихся рукопашным боем, самбо, дзюдо с применением специифических двигательных тренировочных заданий. Содержание предложенной в работе методики развития координачионных способностей предполагает пошаговую педагогическую технологию, включающую: определение понятия координачионной способности,
\end{abstract}

